\title{
MEASURING THE ENVIRONMENTAL IMPACT OF ICT HARDWARE
}

\author{
BARBARA KRUMAY \& ROMAN BRANDTWEINER \\ WU Vienna, Institute for Information Management and Control.
}

\begin{abstract}
Society needs information and communication technology (ICT) hardware to produce, process and store highly valuable information. This hardware, of course, affects the environment throughout its whole life cycle, starting with manufacturing, where the necessary scarce and precious resources (e.g. rare earth metals) are often mined under miserable environmental conditions. This leads to pollution of soil, water and air in the present as well as for the future. During the use phase of ICT hardware, energy consumption impacts the environment. At the end of life of ICT hardware, recycling, disposing as e-waste in landfills or disassembling are additional impacts that affect the environment. More and more producers and users, especially companies, want to measure these impacts, which is a complex task. However, approaches to measure the impacts are at hand, either as single indicators, measuring one specific impact, or as composed indicators, combining different single indicators into one 'summarizing' indicator. However, collection of data, measurement, assessment and interpretation are challenging. Unfortunately, guidelines for those who want to measure the impact of ICT hardware are rare. With our research, we aim to shed light on the various approaches to measure impacts of ICT hardware as well as their application in practice. Based on a literature review, we identified different indicators and them to the attention of experts from companies to assess these approaches in terms of practicability, significance and value for practice. The results show that research investigates and proposes a variety of different more or less complex indicators. However, business prefers single indicators, which are easy to measure and understand.
\end{abstract}

Keywords: impact of ICT hardware, measurement, performance indicators.

\section{INTRODUCTION}

Information and communication technology (ICT) hardware has found its way in our everyday private and business life. However, its extensive use has immense impacts on the environment. Throughout the whole lifecycle, ICT hardware affects the environment. Indicators for measuring those impacts are at hand. However, due to the complexity of ICT hardware, and also because companies prefer to measure by financial and non-financial indicators, which are easier to assess, a clear picture on ICT hardware impact measurement indicators does not exist. In this research, we focus on indicators applied by companies to measure the environmental impacts of ICT hardware. We identified different indicators from literature and brought the resulting approaches to the attention of experts from companies to assess these approaches in terms of practicability, significance and value for practice.

The remainder of the paper is structured as follows: first, we give a short overview on the current state of the field in performance and impact measurement, with special emphasis on ICT hardware. Second, we explain our methodological approach, in particular sampling of the literature and assessment of the indicators found. Third, we present the results, discuss 
them and provide propositions for further research. Finally, we provide a conclusion, limitations and further research.

\section{STATE OF THE FIELD}

Companies adopt different ways to measure their performance and impacts [1]. Results are used as a basis for decision making and changes in the company [2]. On one hand, financial performance is measured to document the success and wealth of a company [2]. Financial performance indicators [3] are the basis for financial reports, which are disclosed to the wider public in accordance with different laws [4]. Special emphasis to assess the success of companies has been put on key performance indicators (KPIs), which measure the critical aspects of companies' performance [5]. Non-financial performance indicators, like customer satisfaction or loyalty, employee training or product quality, have been evidenced to influence companies' success, as well [6]. Furthermore, it has been evidenced that non-financial indicators provide important information for a company in their original, non-peculiar form (e.g. $\mathrm{CO} 2$ emissions in tons per year). However, approaches to monetize such indicators can be observed [5] (e.g. costs evolving from $\mathrm{CO} 2$ emissions in tons per year). Clearly, companies measure their non-financial performance in terms of their impacts on society and environment. This has not always been the case but due to pressure from society in the context of environmentalism [6] and the advent of business ethics and corporate social responsibility (CSR) [7], companies adopt and integrate them in their measurement systems. In many countries, measurement and disclosure of non-financial reports is regulated by laws [8]. However, companies started to voluntarily disclose information beyond the obligatory financial reports [9] in the form of CSR or sustainability reports [7]. Sustainability reports integrate indicators, measuring environmental and societal impacts like greenhouse gas (GHG) emissions or employee satisfaction to state companies' activities in this area [10]. Different indicator schemes, measuring environmental performance such as Environmental Performance Indicators (EPI) [11], Key Ecological Indicators (KEI) or Green Performance Indicators (GPIs) [12], to name just some, are at hand for governments and organizations alike. But still, 'what' and 'how' to measure are open questions requiring further investigation [1]. Although the number of environmental and social indicators seem to be exploding, in the context of green ICT indicators measuring impacts are rare. Green ICT comprises greening by ICT (e.g. environmental information systems) or greening of ICT (reducing environmental impacts of ICT products) [13].

Particularly, the possibilities to reduce environmental impacts of ICT hardware require sound measurement. ICT hardware affects the environment throughout the whole lifecycle. When manufacturing ICT hardware, scarce and precious resources (e.g. rare earth metals) are mined under miserable environmental conditions [14, 15], leading to pollution of soil, water and air [16] in the long term. with usage of computers, power consumption further impacts the environment [17]. At the end of life, the impacts are even more severe, as ICT hardware can be recycled, disposed as e-waste in landfills or disassembled requiring energy and when operated in an inappropriate way, pollutes the environment $[18,19]$. Especially at the end of life, the variety of products (e.g. mobile phones, servers, printers, computers integrated into other products) and different materials integrated (e.g. plastic, metals, liquids) makes measurement of impacts a hard task [20]. Besides the complexity of the product, the lack of green ICT indicators may be other reasons. On one hand, Green ICT is a rather new field [13]; on the other, sustainability frameworks like ISO 14001, the Greenhouse Gas Protocol (GHGP) or the Global Reporting Initiative (GRI) barely address Green ICT [21]. 
All indicators, financial or non-financial, require sound data collection. While accounting systems and enterprise resource planning systems automatically generate data for financial indicators, data for environmental indicators requires additional sources. For both - financial and non-financial indicators - different indicator types are at hand. Single (or pure) indicators measure one specific impact (e.g. CPU power consumption). They can be pure numbers of units (e.g. number of hardware), express relations to other numbers (e.g. number of hardware per user) or time (e.g. number of hardware per year). The number of single indicators used in a company may be enormous, making them hard to understand and maintain. Thus, indicator systems (e.g. DuPont system), composed of compound indicators (e.g. ecological footprint [22]) have been created to assess more complex relationships in a summarizing number. On a more abstract level, symbolic representation of compound indicators, such as the footprint of a human being in terms of resources used, has found attention. Besides those, holistic approaches, integrating financial and non-financial indicators have the potential to overcome disadvantages of pure financial measurement in balancing the different aspects [23]. Especially in the context of ICT hardware, research and business discuss compound and holistic approaches. For example, the Lifecycle Assessment (LCA) tries to integrate all environmental impacts throughout the whole lifecycle [24]. Clearly, producers of different parts that are integrated, have to cooperate and provide according data [25]. Fairphone, (https://www.fairphone.com/projects/life-cycle-assessment/) is an example, produced based on fair, responsible and environmental considerations. In general, indicators for measuring financial performance have been criticized to reduce complex situations to simple numbers [23]. While single financial and non-financial indicators are narrow in their exploratory power, compound indicators are hard to interpret. When the results vary from measurement to measurement it remains unclear which underlying indicator has changed [2].

\section{METHODOLOGICAL APPROACH}

We applied a systematic literature review for identifying indicators for measuring environmental impacts of ICT hardware. First, we identified appropriate search terms based on a short pre-study. Queries included different combinations of Green ICT/IT/IS, ICT/IT hardware, (performance) indicator (performance) measurement, metrics, performance management, environment, energy, pollution as well as scorecard. We applied Boolean operators (AND, OR, NOT) to combine the search terms, on two scientific databases (EBSCO and ABInform/TI ProQuest) in December 2015. The search resulted in 350 academic papers (7 excluded due to language issues). We further selected the papers based on reading the abstract and further reduced the sample to 118 papers. By investigating their content, we excluded all papers that reported performance measurements of governments or pure environmental indicators, not targeting towards ICT hardware. Finally, we identified 59 papers for analyses. Further screening to identify indicators was performed by the co-authors using a software program for content analysis (Atlas.ti).

The results of the literature review were brought to the attention of three experts for assessing their opinion on practicability, significance and value for practice. First, experts were asked to mark the indicators in terms of 'known', 'used by us' (in the company) and 'used by others' (other companies). Second, in a short interview based on rough guidelines, we wanted to identify practicability (efforts for measuring the indicators), significance and value for practice. Interviewees were asked to describe how they think the indicators are or can be used in practice. Finally, to gain a broader understanding on the research-practice gap, we asked them to name other indicators they use and explain the advantages or disadvantages of these 
indicators in brief. All interviews were conducted in the native language of the interviewees, and were audiotaped. Quotations from the interviews have been translated.

\section{RESULTS}

We found 77 different indicators (listed in Appendix A), measuring the impact of ICT hardware in the literature. Hereinafter we refer to them as ICTIMIs (ICT impact measurement indicators). We investigated the literature from different perspectives: resource (energy, water, emissions, waste, other), type of indicator (single, compound, holistic, symbolic measurement), to which ICT hardware they were applied (Specific hardware, Network, Data centers, System/service or general) as well as ICT facilities (e.g. cooling). In addition, we identified whether the ICTIMIs target towards efficiency, consumption or other parameters (e.g. utilization).

Most of the ICTIMIs target towards energy (47) and only a few assess emissions (5), waste (4), water (1) or combinations of them (20). The majority of the ICTIMIs discussed in literature are single indicators (54), have a symbolic representation such as footprint (11), are compound indicators (6) or holistic (6). Concerning hardware, most of the ICTIMIs are general (41) without further specifying on which hardware they are applied, 11 are hardware specific, 9 measure the impacts of networks, systems or services (6), or data centers (5). Some ICTIMIs measure facilities like air-conditioning, space (7), however, 5 of them are only targeting towards facilities, 2 in addition towards data centers. Out of the ICTIMIs identified, 27 measure the consumption, 25 efficiency and 25 target towards other aspects like productivity or utilization to name just some. Figure 1 summarizes the numbers, and a full representation can be found in Appendix A.

The results were brought to the attention of three experts. Expert 1 (E1) has been Chief Security Officer $(\mathrm{CSecO})$ in a transportation company since 2011. The company has about 6000 employees worldwide, using a variety of ICT hardware. Expert 2 (E2) is a consultant for different small- and medium-sized companies. He has been self-employed since 1995. His expertise is especially on network, network equipment and data centers. Most of his

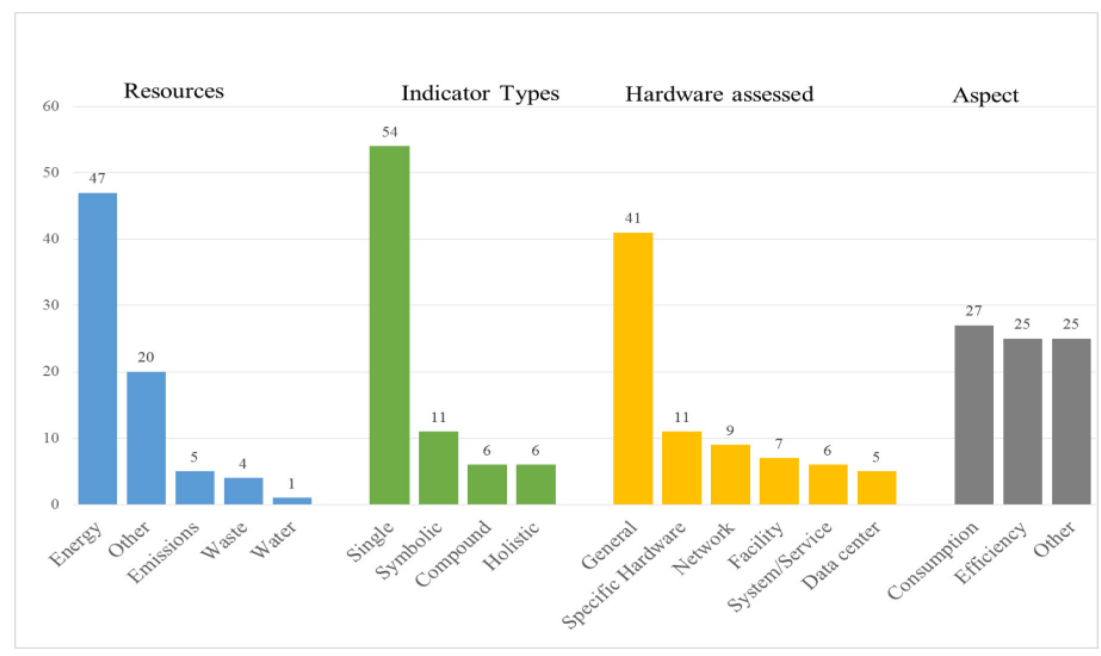

Figure 1: ICTIMIs by resources, type of indicator, hardware assessed, aspect. 
customers are telecommunication companies or internet service providers. Numbers in the table summarize all his current customers. Expert 3 (E3) is Chief Technology Officer (CTO) of a medium-sized company in the retail sector. She has been working in the company since 2000 and in this position since 2013. The company sells hardware and software (see Table 1).

The three experts assessed the list of ICTIMIs quite differently. Concerning marking the indicators in terms of 'known', 'used by us', 'used by others', all experts know about half of the ICTIMIs found (E1: 37; E2: 42; E3: 32). However, Expert 1 mainly knows indicators for measuring energy efficiency in general. Expert 2, by contrast, knows many of the indicators, but in the companies he is working with, he uses only 13, mainly addressing networks and data center efficiency. Expert 3, is aware of many footprint indicators, but has neither used them nor have seen them used. Most well-known and applied indicators are CPU usage efficiency, energy efficiency, energy efficiency of data centers, paper used for printing, PC power management, PUE, ScE. Although they know some indicators (e.g. Green IT BSC), they do not apply them. The ratio between indicators known and indicators used varies from 0.65 (E1), 0.47 (E3) to 0.41 (E2), whereas the ratio between knowing and used by other companies is slightly higher (E1: 0.78; E2: 0.62; 0.88). Table 2 summarizes the results; Appendix A represents all results.

Table 1: Characteristics of experts.

\begin{tabular}{lccc}
\hline & E1 & E2 & E3 \\
\hline Position & CSecO & Consultant & CTO \\
In the company since & 1990 & 1995 & 2000 \\
In this position since & 2011 & 1995 & 2013 \\
Industry & Transportation & ICT & Retail \\
Employees (approx.) & 6000 & - & 320 \\
IT hardware & 300 servers, & 450 servers & 5 servers \\
& 7 networks, & 12 networks & 1 network \\
& 30 000 devices & 4 500 devices & 500 devices \\
& 2 data centers & 5 data centers & 2 data centers \\
\hline
\end{tabular}

Table 2: Summary of Experts' Assessment of ICTIMIs.

\begin{tabular}{|c|c|c|c|c|c|}
\hline & E1 & E2 & E3 & Indicators unknown & 24 \\
\hline Known (K) & 37 & 42 & 32 & Known by one expert & 20 \\
\hline Used by us $\left(\mathrm{U}_{\mathrm{U}}\right)$ & 20 & 13 & 15 & Known by two experts & 8 \\
\hline Used by others $\left(\mathrm{U}_{\mathrm{O}}\right)$ & 29 & 26 & 28 & Known by all experts & 25 \\
\hline Ratio $\mathrm{U}_{\mathrm{U}} / \mathrm{K}$ & 0.65 & 0.41 & 0.47 & & \\
\hline Ratio $\mathrm{U}_{\mathrm{O}} / \mathrm{K}$ & 0.78 & 0.62 & 0.88 & & \\
\hline
\end{tabular}


In the interviews, the experts expressed their points of view on practicability, significance and value for practice. All three explained that compound indicators such as footprints are not useful for them because they are 'hard to assess and even harder to understand' (E2). The same applies to holistic approaches like LCA or the Green IT BSC. Expert 1 mentioned that they started a project to set up the lifecycle assessment for one specific hardware they bought, but 'due to the massive amount of data needed, we stopped it'. Furthermore, Expert 1 specifically expressed that the Green IT BSC 'is too complicated and requires a lot of resources to collect the necessary data'. Expert 3 mentioned that they do not use the balanced scorecard approach in their company, so there is no basis for the Green IT BSC. All experts expressed their preference for single performance indicators, especially energy measures. Furthermore, they found it important that collection data, calculation and monitoring operate automatically. Expert 2 mentioned that 'the data to measure CPU usage efficiency, for example, can be collected automatically via integrated protocols making monitoring easy - that is why we use it'. All three agreed upon energy being the most significant resource measured, since 'energy means money' (E3). However, Expert 2 reported that one of his customers stopped measuring the energy efficiency of servers since it influenced the general performance. Expert 1 made a similar statement by explaining 'that we only measure where it has not influence on the performance'. All three experts expressed that some results from measuring impacts of ICT hardware are published in internal or external sustainability reports (e.g. PUE), but only because they were existing. When buying new hardware, labels like the energy star are 'somehow relevant, but price and functionality are more important' (E3). Expert 3 mentioned, that 'especially the PUE and similar indicators were helpful when we set up our new data center'. When asking them to name indicators not listed in our results, Expert 1 named very generally 'indicators from ITIL, COBIT or ISO 14001', whereas Expert 3 came up with a list of six indicators, she could name by heart, because they are 'extensively used in the company' (see Table 3). Only Expert 2 did not name any indicators, but explained that

Table 3: List of Indicators (Expert 3).

\begin{tabular}{|c|c|c|c|c|c|c|c|c|c|c|}
\hline & 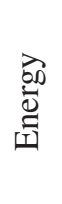 & $\begin{array}{l}\overline{\grave{D}} \\
\stackrel{\Xi}{0}\end{array}$ & $\begin{array}{l}\stackrel{0}{\not \infty} \\
\stackrel{0}{\Xi}\end{array}$ & 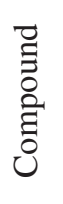 & $\begin{array}{l}\bar{\pi} \\
\stackrel{\pi}{0} \\
0 \\
0\end{array}$ & 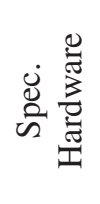 & 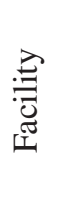 & 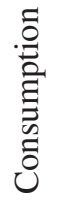 & 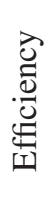 & $\frac{\overline{0}}{\stackrel{ \pm}{0}}$ \\
\hline Paper pages per employee & & $\mathrm{x}$ & $\mathrm{X}$ & & & & & & & \\
\hline $\begin{array}{l}\text { Percentage of energy used from } \\
\text { renewable sources }\end{array}$ & $\mathrm{x}$ & & $\mathrm{X}$ & & & & & & & \\
\hline Percentage of recycled printer paper & & $\mathrm{x}$ & $\mathrm{X}$ & & & & & & & \\
\hline \multicolumn{11}{|l|}{ Renewable energy use } \\
\hline Software sustainability index & & $\mathrm{x}$ & & $\mathrm{x}$ & & & & & & \\
\hline Watts per Active Port & $\mathrm{x}$ & & $\mathrm{X}$ & & & & & & & \\
\hline
\end{tabular}


'indicators have to fit to the company and depend on the requirements and specifications'. Interestingly, Expert 1 explained that there is no plan or strategic decision on indicators used to measure impacts of ICT hardware. Some are measured 'because we know how to measure them' (E1), 'we can visualize them in the dash board' (E2) or 'they have always been measured' (E3). Out of the list of ICTIMIs from literature, none seemed to be interesting at the current state. Experts 1 and 3 expressed that they would use repositories of ICTIMIs, but they were not aware of an existing one.

\section{DISCUSSION AND PROPOSITIONS}

With our research, we aim to shed light on the approaches to measure impacts of ICT hardware as well as their application in practice. Our research revealed that academic literature discusses a respectable number of different indicators. However, the experts in our study were not aware of many of the indicators developed from literature. Although well known, complex compound indicators such as the LCA and the Green IT BSC are rarely applied in practice. Practice by contrast applies indicators, which are easy to measure and understand. In research and practice, measuring efficiency and consumption of energy dominates by far measurement of other resources. This may be because energy measurement is directly connected to cost considerations. In general, we see that companies have adopted some ICTIMIs, but reasons for their implementation remain unclear. Hence, we contribute to research and practice alike. For research, the propositions may foster as a starting point whereas practical implications arise from the knowledge gained concerning factors influencing ICTIMIs application.

Experts know more than the half of the indicators collected from literature, but apply only a few of them. Based on the interviews, we conclude that several factors influence the application of ICTIMIs. First, it is their practicability. When the data for the ICTIMIs can be easily collected, best case automatically, they have a good chance to be applied. This is clearly connected to what has been said before about financial indicators, where the data is collected or created almost automatically by accounting systems [2]. Second, the experts in this study expressed that the priority is on the performance of hardware, not on measuring impacts. Companies that need to have clear and understandable indicators also explain the reluctance of the experts to implement compound indicators, indicator systems and holistic approaches. Other research already revealed that compound indicators such as the ecological footprint are often used on the governmental level, but not on the company level. Hence, we postulate:

Proposition 1: Easy collection of data, no or low influence on the performance of the hardware measured as well as easy to understand results are factors influencing the application of ICTIMIs in companies.

As we have seen in the literature review and learned from the experts, energy efficiency and consumption are in focus. First, energy consumption is easy to measure, but second and even more important, decrease of energy consumption immediately reduces costs. This is somehow in line with research, where monetarization of non-monetary indicators has been discussed lengthily [5]. Reasons for these efforts may lie in the long tradition of financial indicators, the current economic system or the need to be comparable with other competitors. However, we propose:

Proposition 2: Adoption of ICTIMIs with a clear and direct connection to monetary consequences (costs, savings) will be more likely compared to non-pecuniary ICTIMIs. 
Interestingly, the experts in this study did not express any strategic considerations for implementing ICTIMIs. This is somewhat contradictory to results from research, since the responsibility for the selection of performance indicators is often seen as a strategic task [2]. In the rather new area of 'greening ICT', other factors influence the selection of ICTIMIs. First, pragmatic considerations like employee knowledge on the measurement are more important. Second, the fit to operational requirements for monitoring (like visualization) plays an important role. Third, a kind of convenience also influences the selection (e.g. 'have always been measured', 'is implemented into the hardware'). It is important to make clear that ICTIMIs are not randomly selected, because - as already described in proposition 1 and 2 - several factors influence the implementation and application. Consequently, we state:

Proposition 3: Pragmatic considerations, fit of ICTIMIs to companies' operational requirements as well as convenience influence the implementation of ICTIMIs more than strategic considerations.

\section{CONCLUSION, LIMITATIONS AND FUTURE RESEARCH}

Measuring the impacts of ICT hardware is a complex task. As we have shown, different approaches are at hand, but application in practice is rare. Main factors for adoption in practice are measurability and fit to task. Of course, this research has some limitations. First, due to the mere exploratory nature of our research, we did not test our assumptions and proposition. Second, the number of experts is rather low. A quantitative evaluation could be helpful to gain broader understanding. Our literature review serves as a solid basis for further research on privacy and security performance indicators. Future research should focus on the applicability of ICTIMIs as well as on testing the propositions mentioned above.

\section{REFERENCES}

[1] Neely, A., The performance measurement revolution: why now and what next? International Journal of Operations \& Production Management, 19(2), pp. 205-228, 1999. http://dx.doi.org/10.1108/01443579910247437

[2] Venkatraman, N. \& Ramanujam, V., Measurement of business performance in strategy research: a comparison of approaches. Academy of Management Review, 11(4), pp. 801-814, 1986.

[3] Neely, A.D., Business Performance Measurement: Theory and Practice, Cambridge University Press, 2002.

[4] Healy, P.M. \& Palepu, K.G., The effect of firms' financial disclosure strategies on stock prices. Accounting Horizons, 7(1), p. 1, 1993.

[5] Parmenter, D., Key Performance Indicators (KPI): Developing, Implementing, and Using Winning KPIs, John Wiley \& Sons, 2010.

[6] van Rekom, J., Go, F.M. \& Calter, D.M., Communicating a company's positive impact on society-can plausible explanations secure authenticity? Journal of Business Research, 67(9), pp. 1831-1838, 2014. http://dx.doi.org/10.1016/j.jbusres.2013.12.006

[7] Caritte, V., Acha, S. \& Shah, N., Enhancing corporate environmental performance through reporting and roadmaps. Business Strategy \& the Environment, 24(5), pp. 289-308, 2015.

http://dx.doi.org/10.1002/bse.1818 
[8] Nnorom, I.C. \& Osibanjo, O., Overview of electronic waste (e-waste) management practices and legislations, and their poor applications in the developing countries. Resources, Conservation and Recycling, 52(6), pp. 843-858, 2008. http://dx.doi.org/10.1016/j.resconrec.2008.01.004

[9] Dhaliwal, D.S., Li, O.Z., Tsang, A. \& Yang, Y.G., Voluntary nonfinancial disclosure and the cost of equity capital: the initiation of corporate social responsibility reporting. The Accounting Review, 86(1), pp. 59-100, 2011. http://dx.doi.org/10.2308/accr.00000005

[10] Wallström, M., Active or reactive - CSR reporting and sustainable development as tools for smart growth, In GRI Conference - Reporting Sustainability, V.P.o.t.E.C.r.f.I.R.a.C. Strategy, Editor: Amsterdam, 2006.

[11] Hammond, A.L. \& Institute, W.R., Environmental Indicators: a Systematic Approach to Measuring and Reporting on Environmental Policy Performance in the Context of Sustainable Development, World Resources Institute Washington, DC, 1995.

[12] Ferreira, A.M. \& Pernici, B., Managing the complex data center environment: an integrated energy-aware framework. Computing, pp. 1-41, 2014.

http://dx.doi.org/10.1007/s00607-014-0405-x

[13] Mickoleit, A., Greener and Smarter. ICTs, the Environment and Climate Change, OECD, Editor, 2010.

[14] Alonso, E., Sherman, A.M., Wallington, T.J., Everson, M.P., Field, F.R., Roth, R. \& Kirchain, R.E., Evaluating rare earth element availability: a case with revolutionary demand from clean technologies. Environmental Science \& Technology, 46(6), pp. 3406-3414, 2012. http://dx.doi.org/10.1021/es203518d

[15] Schüler, D., Buchert, M., Liu, R., Dittrich, S. \& Merz, C., Study on Rare Earths and their Recycling, Ö.-I. eV, Editor. Darmstadt, 2011.

[16] Humphries, M., Rare earth elements: the global supply chain. CRS Report for Congress, ed. C.R. Service, DIANE Publishing: Washington, 2010.

[17] Bertoldi, P. \& Atanasiu, B., Electricity consumption and efficiency trends in the enlarged European union, In JRC Scientific and Technical Reports, European Commission Joint Research Centre Institute for Energy: Luxembourg, 2009.

[18] Cairns, C.N., E-waste and the consumer: improving options to reduce, reuse and recycle. Electronics and the Environment, 2005. Proceedings of the 2005 IEEE International Symposium on, IEEE, pp. 237-242, 2005.

http://dx.doi.org/10.1109/ISEE.2005.1437033

[19] Boudier, F. \& Bensebaa, F., Hazardous waste management and corporate social responsibility: illegal trade of electrical and electronic waste. Business \& Society Review, 116(1), pp. 29-53, 2011. http://dx.doi.org/10.1111/j.1467-8594.2011.00376.x

[20] Robinson, B.H., E-waste: an assessment of global production and environmental impacts. Science of the Total Environment, 408(2), pp. 183-191, 2009. http://dx.doi.org/10.1016/j.scitotenv.2009.09.044

[21] GRI Global Reporting Initiative, Global Reporting Guidelines, 2014 available at https://www.globalreporting.org/resourcelibrary/GRIG4-Part1-Reporting-Principlesand-Standard-Disclosures.pdf 
[22] Wackernagel, M. \& Rees, W., Our Ecological Footprint: Reducing Human Impact on the Earth, New Society Publishers, 1998.

[23] Bird, S.M., David, C., Farewell, V.T., Harvey, G., Tim, H. \& Peter, C., Performance indicators: good, bad, and ugly. Journal of the Royal Statistical Society: Series A (Statistics in Society), 168(1), pp. 1-27, 2005.

http://dx.doi.org/10.1111/j.1467-985X.2004.00333.x

[24] Blengini, G.A., Fantoni, M., Busto, M., Genon, G. \& Zanetti, M.C., Participatory approach, acceptability and transparency of waste management LCAs: case studies of Torino and Cuneo. Waste Management, 32(9), pp. 1712-1721, 2012. http://dx.doi.org/10.1016/j.wasman.2012.04.010

[25] Lenzen, M., Murray, J., Sack, F. \& Wiedmann, T., Shared producer and consumer responsibility-theory and practice. Ecological Economics, 61(1), pp. 27-42, 2007.

http://dx.doi.org/10.1016/j.ecolecon.2006.05.018

Appendix A: List of Indicators

\begin{tabular}{|c|c|c|c|c|c|c|c|}
\hline & 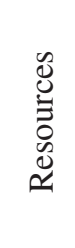 & 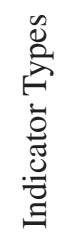 & 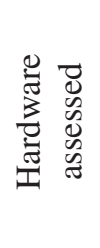 & 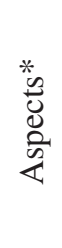 & 㫄 & 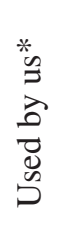 & 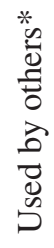 \\
\hline APC - Area Power consumption & En & $\mathrm{Si}$ & $\mathrm{Ge}$ & Cs & 0 & 0 & 0 \\
\hline $\begin{array}{l}\text { Availability of formal environmental technology } \\
\text { procedures }\end{array}$ & $\mathrm{O}_{\mathrm{R}}$ & $\mathrm{Si}$ & $\mathrm{Ge}$ & $\mathrm{O}_{\mathrm{A}}$ & 0 & 0 & 0 \\
\hline CADE - Corporate Average Data Efficiency & $\mathrm{O}_{\mathrm{R}}$ & Co & DC & $\mathrm{Ef}$ & 3 & 0 & 2 \\
\hline Carbon footprint / CO2 footprint & Em & Sy & $\mathrm{Ge}$ & Cs & 2 & 0 & 0 \\
\hline $\begin{array}{l}\text { Carbon footprint of digital information services / } \\
\text { storage }\end{array}$ & Em & Sy & $\mathrm{Se}$ & Cs & 0 & 0 & 0 \\
\hline Cloud computing energy efficiency & En & $\mathrm{Si}$ & $\mathrm{Se}$ & Ef & 2 & 1 & 1 \\
\hline Cooling System Efficiency & En & $\mathrm{Si}$ & $\mathrm{Fa}$ & Ef & 3 & 1 & 2 \\
\hline CPE - Compute Power Efficiency & En & $\mathrm{Si}$ & $\mathrm{Ge}$ & Ef & 1 & 0 & 1 \\
\hline CPU usage efficiency & En & $\mathrm{Si}$ & $\mathrm{SH}$ & Ef & 3 & 3 & 3 \\
\hline CUE - Carbon Usage Effectiveness & Em & $\mathrm{Si}$ & $\mathrm{Ge}$ & Ef & 1 & 0 & 0 \\
\hline Data centre physical footprint & $\mathrm{O}_{\mathrm{R}}$ & Sy & DC & Cs & 1 & 0 & 0 \\
\hline DCiE - Data Centre infrastructure Efficiency & En & $\mathrm{Si}$ & $\mathrm{Fa}$ & Ef & 3 & 2 & 3 \\
\hline DCP - Data Centre Productivity & En & $\mathrm{Si}$ & $\mathrm{DC}^{*}$ & $\mathrm{O}_{\mathrm{A}}$ & 1 & 0 & 0 \\
\hline DPPE - Data Centre Performance Per Energy & En & $\mathrm{Si}$ & $\mathrm{DC}^{*}$ & $\mathrm{O}_{\mathrm{A}}$ & 0 & 0 & 0 \\
\hline
\end{tabular}




\begin{tabular}{|c|c|c|c|c|c|c|c|}
\hline & 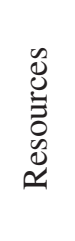 & 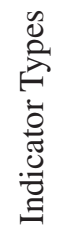 & 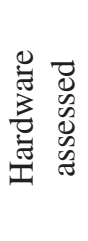 & 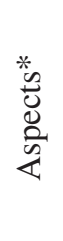 & 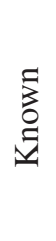 & 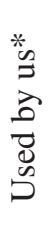 & 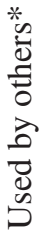 \\
\hline ECG - Energy Consumption Gain & En & $\mathrm{Si}$ & $\mathrm{Ge}$ & Cs & 1 & 0 & 0 \\
\hline Ecological footprint & $\mathrm{O}_{\mathrm{R}}$ & Sy & $\mathrm{Ge}$ & Cs & 3 & 0 & 0 \\
\hline ECR - Energy Consumption Rating & En & $\mathrm{Si}$ & $\mathrm{Ne}$ & Cs & 0 & 0 & 0 \\
\hline ECRW - ECR-Weighted & En & $\mathrm{Si}$ & $\mathrm{Ne}$ & Cs & 1 & 0 & 0 \\
\hline EE - Energy efficiency & En & $\mathrm{Si}$ & $\mathrm{Ge}$ & Ef & 3 & 3 & 3 \\
\hline $\mathrm{EE}$ in data centres & En & $\mathrm{Si}$ & $\mathrm{Se}$ & Ef & 3 & 3 & 3 \\
\hline EE of (mobile sensor) networks & En & $\mathrm{Si}$ & $\mathrm{Ne}$ & Ef & 2 & 0 & 2 \\
\hline EE of ICT operation & En & $\mathrm{Si}$ & $\mathrm{SE}$ & Ef & 3 & 2 & 3 \\
\hline EE of ICT products & En & $\mathrm{Si}$ & $\mathrm{Ge}$ & Ef & 0 & 0 & 0 \\
\hline EE of infrastructure & En & $\mathrm{Si}$ & SH & Ef & 3 & 2 & 3 \\
\hline EE of Location Based Services & En & $\mathrm{Si}$ & $\mathrm{Se}$ & Ef & 0 & 0 & 0 \\
\hline EE of systems & En & $\mathrm{Si}$ & $\mathrm{Se}$ & Ef & 3 & 2 & 3 \\
\hline EE of terminals & En & $\mathrm{Si}$ & SH & Ef & 0 & 0 & 0 \\
\hline Energy footprint & En & Sy & $\mathrm{Ge}$ & Cs & 0 & 0 & 0 \\
\hline Energy star & En & Co & $\mathrm{Ge}$ & $\mathrm{O}_{\mathrm{A}}$ & 3 & 0 & 3 \\
\hline EnergyBench - Throughput of Joule for computing & En & $\mathrm{Si}$ & $\mathrm{Ge}$ & Cs & 0 & 0 & 0 \\
\hline Environmental footprint & $\mathrm{O}_{\mathrm{R}}$ & Sy & $\mathrm{Ge}$ & Cs & 1 & 0 & 1 \\
\hline Environmental impact assessment & $\mathrm{O}_{\mathrm{R}}$ & Ho & $\mathrm{Ge}$ & $\mathrm{O}_{\mathrm{A}}$ & 3 & 0 & 0 \\
\hline EPI - Energy Proportionality Index & En & $\mathrm{Si}$ & $\mathrm{Ge}$ & $\mathrm{O}_{\mathrm{A}}$ & 0 & 0 & 0 \\
\hline $\begin{array}{l}\text { ERF - Energy Reuse Factor: Amount of reusable } \\
\text { energy }\end{array}$ & En & $\mathrm{Si}$ & $\mathrm{Ge}$ & $\mathrm{O}_{\mathrm{A}}$ & 2 & 0 & 0 \\
\hline ESI - Energy scaling index & En & $\mathrm{Si}$ & SH & Ef & 1 & 0 & 0 \\
\hline E-Waste per unit & Wa & $\mathrm{Si}$ & $\mathrm{Ge}$ & $\mathrm{O}_{\mathrm{A}}$ & 3 & 1 & 2 \\
\hline GHG footprint & Em & Sy & $\mathrm{Ge}$ & Cs & 3 & 0 & 3 \\
\hline Global footprint & Em & Sy & $\mathrm{Ge}$ & Cs & 3 & 0 & 3 \\
\hline
\end{tabular}




\begin{tabular}{|c|c|c|c|c|c|c|c|}
\hline & 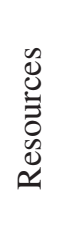 & 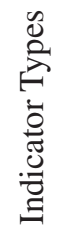 & 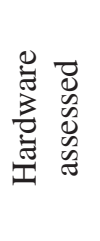 & 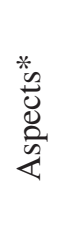 & 泀 & 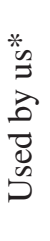 & 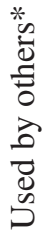 \\
\hline Green IT BSC (Green IT Balanced Scorecard) & $\mathrm{O}_{\mathrm{R}}$ & Ho & $\mathrm{Ge}$ & $\mathrm{O}_{\mathrm{A}}$ & 3 & 0 & 2 \\
\hline Hazardous waste ratings & Wa & $\mathrm{Si}$ & $\mathrm{Ge}$ & $\mathrm{O}_{\mathrm{A}}$ & 0 & 0 & 0 \\
\hline $\begin{array}{l}\text { HVAC - Heating Ventilation Air-conditioning } \\
\text { Effectiveness }\end{array}$ & En & $\mathrm{Si}$ & $\mathrm{Fa}$ & Ef & 2 & 2 & 2 \\
\hline ICT sector footprint / ICT's environmental footprint & $\mathrm{O}_{\mathrm{R}}$ & Sy & $\mathrm{Ge}$ & Cs & 1 & 0 & 0 \\
\hline ISO 14001 certification & $\mathrm{O}_{\mathrm{R}}$ & $\mathrm{Co}$ & $\mathrm{Ge}$ & $\mathrm{O}_{\mathrm{A}}$ & 3 & 2 & 3 \\
\hline ITEE - IT Equipment Energy Efficiency & En & $\mathrm{Si}$ & $\mathrm{Ge}$ & Ef & 1 & 1 & 0 \\
\hline ITEU - IT Equipment Utilization & & $\mathrm{Si}$ & $\mathrm{Ge}$ & $\mathrm{O}_{\mathrm{A}}$ & 1 & 1 & 0 \\
\hline $\begin{array}{l}\text { Joulesort - Amount of energy required to sort } \\
\text { different size of records in data centre }\end{array}$ & En & $\mathrm{Si}$ & $\mathrm{Ge}$ & Cs & 0 & 0 & 0 \\
\hline LCA - Lifecycle Assessment & $\mathrm{O}_{\mathrm{R}}$ & Ho & $\mathrm{Ge}$ & $\mathrm{O}_{\mathrm{A}}$ & 3 & 0 & 3 \\
\hline LCA of supply chains & $\mathrm{O}_{\mathrm{R}}$ & Ho & $\mathrm{Ge}$ & $\mathrm{O}_{\mathrm{A}}$ & 3 & 0 & 3 \\
\hline Material Flow Analysis & $\mathrm{O}_{\mathrm{R}}$ & Ho & $\mathrm{Ge}$ & Cs & 3 & 0 & 3 \\
\hline Memory footprint & $\mathrm{O}_{\mathrm{R}}$ & Sy & $\mathrm{Ge}$ & Cs & 0 & 0 & 0 \\
\hline Mobile Energy Efficiency network Benchmarking & En & Co & $\mathrm{Ne}$ & Ef & 0 & 0 & 0 \\
\hline NPC - Normalized Power Consumption & En & $\mathrm{Si}$ & $\mathrm{Ge}$ & Cs & 0 & 0 & 0 \\
\hline Number of IT environmental award & $\mathrm{O}_{\mathrm{R}}$ & $\mathrm{Si}$ & $\mathrm{Ge}$ & $\mathrm{O}_{\mathrm{A}}$ & 0 & 0 & 0 \\
\hline Number of IT environmental certificates & $\mathrm{O}_{\mathrm{R}}$ & $\mathrm{Si}$ & $\mathrm{Ge}$ & $\mathrm{O}_{\mathrm{A}}$ & 0 & 0 & 0 \\
\hline Number of trainings related to green technology usage & $\mathrm{O}_{\mathrm{R}}$ & $\mathrm{Si}$ & $\mathrm{Ge}$ & $\mathrm{O}_{\mathrm{A}}$ & 0 & 0 & 0 \\
\hline Obsolescence Indication & $\mathrm{Wt}$ & $\mathrm{Si}$ & $\mathrm{Ge}$ & $\mathrm{O}_{\mathrm{A}}$ & 1 & 1 & 1 \\
\hline Paper used for printing & Wa & $\mathrm{Si}$ & $\mathrm{SH}$ & Cs & 3 & 3 & 3 \\
\hline PBBline - Power consumption per line of Broadband & En & $\mathrm{Si}$ & $\mathrm{Ne}$ & Cs & 0 & 0 & 0 \\
\hline PC Power Management & En & Co & $\mathrm{SH}$ & $\mathrm{O}_{\mathrm{A}}$ & 3 & 3 & 3 \\
\hline Power footprint of picocell & En & Sy & $\mathrm{Ne}$ & Cs & 0 & 0 & 0 \\
\hline $\begin{array}{l}\text { Power per User Ratio of total power consumed w.r.t } \\
\text { number of subscribers }\end{array}$ & En & $\mathrm{Si}$ & $\mathrm{Ge}$ & Cs & 0 & 0 & 0 \\
\hline
\end{tabular}




\begin{tabular}{|c|c|c|c|c|c|c|c|}
\hline & $\begin{array}{l}\mathscr{d} \\
\stackrel{0}{0} \\
0 \\
0 \\
\tilde{d}\end{array}$ & 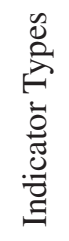 & 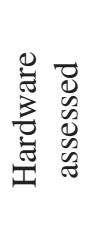 & 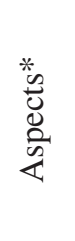 & 㫄 & 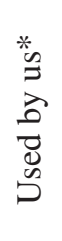 & 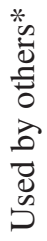 \\
\hline PUE Power Usage Effectiveness & En & $\mathrm{Si}$ & DC & Ef & 3 & 3 & 2 \\
\hline Recycling Rate & Wa & $\mathrm{Si}$ & $\mathrm{Ge}$ & $\mathrm{O}_{\mathrm{A}}$ & 2 & 2 & 2 \\
\hline Risk technology assessment & $\mathrm{O}_{\mathrm{R}}$ & Ho & $\mathrm{Ge}$ & $\mathrm{O}_{\mathrm{A}}$ & 2 & 0 & 0 \\
\hline ScE - Server Compute Efficiency & En & $\mathrm{Si}$ & SH & Ef & 3 & 3 & 3 \\
\hline $\begin{array}{l}\text { SPECPower - Power consumption per server on a } \\
\text { given workload to complete }\end{array}$ & En & $\mathrm{Si}$ & SH & Cs & 1 & 0 & 1 \\
\hline Sustainability performance record & $\mathrm{O}_{\mathrm{R}}$ & Co & $\mathrm{Ge}$ & $\mathrm{O}_{\mathrm{A}}$ & 0 & 0 & 0 \\
\hline SWaP - Space Wattage and Performance & En & $\mathrm{Si}$ & $\mathrm{Fa}$ & Cs & 1 & 0 & 0 \\
\hline $\begin{array}{l}\text { TDP - Thermal Design Power: maximum amount of } \\
\text { heat generated for which the cooling system is required }\end{array}$ & En & $\mathrm{Si}$ & $\mathrm{Fa}$ & $\mathrm{O}_{\mathrm{A}}$ & 0 & 0 & 0 \\
\hline $\begin{array}{l}\text { TEEER - Telecommunications Equipment Energy } \\
\text { Efficiency Ratio }\end{array}$ & En & $\mathrm{Si}$ & SH & Ef & 1 & 1 & 1 \\
\hline TEER - Telecommunications Energy Efficiency Ratio & En & $\mathrm{Si}$ & SH & Ef & 1 & 1 & 1 \\
\hline TPC - Total Power Consumption & En & $\mathrm{Si}$ & $\mathrm{Ge}$ & Cs & 1 & 1 & 1 \\
\hline UPS System Efficiency & En & $\mathrm{Si}$ & $\mathrm{SH}$ & Ef & 2 & 1 & 1 \\
\hline Utilization of ICT & $\mathrm{O}_{\mathrm{R}}$ & $\mathrm{Si}$ & $\mathrm{Ge}$ & $\mathrm{O}_{\mathrm{A}}$ & 1 & 1 & 1 \\
\hline Wake on LAN & En & $\mathrm{Si}$ & $\mathrm{Ne}$ & $\mathrm{O}_{\mathrm{A}}$ & 3 & 0 & 2 \\
\hline WattsPerMAC Watts Per MAC port & En & $\mathrm{Si}$ & $\mathrm{Ne}$ & Cs & 1 & 1 & 1 \\
\hline WattsPerVLL (Virtual Leased Line) & En & $\mathrm{Si}$ & $\mathrm{Ne}$ & Cs & 1 & 1 & 1 \\
\hline
\end{tabular}

Legend:

- Resources: En - Energy (47); $\mathrm{O}_{\mathrm{R}}$ - Other resources (20); Em - Emissions (5)Wa Waste (4); Wt - Water (1)

- Indicator Types: $\mathrm{Si}$ - single (54); Sy - symbolic (11); Co - compound (6); Ho Holistic (6);

- Hardware assessed: Ge - General (41); SH - Specific Hardware (11); Ne - Network (9); $\mathrm{Fa}$ - Facility (7); Se - Systems and Services (6); DC - Data Center (5);

- Aspects: Cs - Consumption (27); Ef - Efficiency (25); $\mathrm{O}_{\mathrm{A}}$ - other aspects (25)

* number of experts 